\title{
Expanding Endovascular Therapy of Very Small Ruptured Aneurysms with the 1.5-mm Coil
}

\author{
Thanh N. Nguyen ${ }^{a-c}$ Hesham Masoud ${ }^{a, c}$ Nicholas Tarlov ${ }^{d, e}$ \\ James Holsapple $^{b}$ Lawrence S. Chin ${ }^{f}$ Alexander M. Norbash ${ }^{c}$ \\ Departments of a Neurology, ${ }^{b}$ Neurosurgery, and ${ }^{\mathrm{c}}$ Radiology, Boston University School of \\ Medicine, Boston Mass., Departments of ${ }^{\mathrm{d}}$ Neurology and ${ }^{\mathrm{N}}$ Neurosurgery, Desert Regional \\ Medical Center, Palm Springs, Calif., and fDepartment of Neurosurgery, SUNY Upstate \\ Medical University, Syracuse, N.Y., USA
}

\section{Key Words}

Very small ruptured aneurysms · Endovascular therapy · Coil embolization

\begin{abstract}
Background: Very small ruptured aneurysms $(\leq 3 \mathrm{~mm})$ demonstrate a significant risk for procedural rupture with endovascular therapy. Since 2007, 1.5-mm-diameter coils have been available (Micrus, Microvention, and ev3), allowing neurointerventionalists the opportunity to offer patients with very small aneurysms endovascular treatment. In this study, we review the clinical and angiographic outcome of patients with very small ruptured aneurysms treated with the 1.5-mm coil. Methods: This is a retrospective cohort study in which we examined consecutive ruptured very small aneurysms treated with coil embolization at a single institution. The longest linear aneurysm was recorded, even if the first coil was sized to a smaller transverse diameter. Very small aneurysms were defined as $\leq 3 \mathrm{~mm}$. Descriptive results are presented. Results: From July 2007 to March 2015, 81 aneurysms were treated acutely with coils in 78 patients presenting with subarachnoid hemorrhage. There were 5 patients with $3-\mathrm{mm}$ aneurysms, of which the transverse diameter was $\leq 2 \mathrm{~mm}$ in 3 patients. In all 5 patients, a balloon was placed for hemostatic prophylaxis in case of rupture, and a single $1.5-\mathrm{mm}$ coil was inserted for aneurysm treatment without complication. Complete aneurysm occlusion was achieved in 1 patient, residual neck in 2, and residual aneurysm in 2 patients. Aneurysm recanalization was present in 2 patients with an anterior communicating artery aneurysm; a recoiling attempt was unsuccessful in 1 of these 2 patients due to inadvertent displacement and distal coil embolization, but subsequent surgical clipping was successful. Another patient was retreated by surgical clipping for a residual wide-neck carotid terminus aneurysm. One patient died of ventriculitis 3 weeks after presentation; all 4 other patients had an excellent
\end{abstract}


outcome with no rebleed at follow-up (mean 21 months, range 1-62). Conclusion: The advent of the $1.5-\mathrm{mm}$ coil may be used in the endovascular treatment of patients with very small ruptured aneurysms, providing a temporary protection to the site of rupture in the acute phase. If necessary, bridging with elective clipping may provide definitive aneurysm treatment.

(C) 2015 S. Karger AG, Basel

\section{Introduction}

The International Subarachnoid Aneurysm Trial (ISAT) [1, 2] established the benefit of coiling for patients with ruptured aneurysms when compared with clipping. Very small ruptured aneurysms $(\leq 3 \mathrm{~mm})$ were not included in this study, and no firm conclusion could be drawn as to whether coiling was beneficial in this particular subgroup of patients. Subsequent patient series demonstrated a significant risk for procedural rupture with endovascular therapy of very small ruptured aneurysms $[3,4]$. When a patient is being considered for coiling, the smallest aneurysm transverse diameter is considered in order to calculate the largest coil diameter size, to avoid inserting a coil larger than the diameter of the aneurysm. Not infrequently, the transverse diameter of the aneurysm is $<2 \mathrm{~mm}$, which may exclude a patient from consideration for endovascular therapy.

Since 2007, 1.5-mm-diameter coils have been available (Micrus, Microvention, and ev3), allowing neurointerventionalists the opportunity to offer coiling to more patients with very small aneurysms who otherwise would have been triaged for surgical clipping. In this study, we review the clinical and angiographic outcome of patients with very small ruptured aneurysms treated with the $1.5-\mathrm{mm}$ coil as a primary framing coil.

\section{Methods}

Patients and Aneurysms

This is a retrospective cohort study in which we examined consecutive ruptured very small aneurysms treated with coil embolization from a prospectively collected database between July 2007 and March 2015. Patients were considered after consensus had been reached between the attending neurosurgeon and neurointerventionalist in favor of endovascular treatment. In general, most patients were triaged to endovascular therapy unless the anatomy was unfavorable, such as patients with wide-neck aneurysms or access, vessel tortuosity, or patients with middle cerebral artery (MCA) aneurysms in whom we typically favored surgery.

The largest aneurysm size was recorded, even if the first coil was sized to a smaller transverse diameter. The aneurysm size was measured by 3D reconstruction and corrected according to a comparison with the diameter of the first coil used. Very small aneurysms were defined as $\leq 3 \mathrm{~mm}$ in maximum linear dimension. Descriptive results are presented (table 1).

\section{Endovascular Treatment}

All patients were treated under general anesthesia. A ventricular drain was placed in 4 patients (in 3 patients for symptomatic hydrocephalus, in 1 patient for perceived risk of procedural rupture) prior to coiling. Heparin was administered after femoral puncture or first coil placement to target activated clotting time $>250$ s. Protamine was prepared in each case in the event of procedural rupture. Procedures were performed on a monoplane C-arm angiographic system with 3D reconstruction and 3D road map capability. Multiple projections were used to identify the best angle of incidence to display the aneurysm neck.

Coil insertion was performed using platinum coils (Micrus coils; Codman Therapeutics, Raynham, Mass., USA) with an SL-10 microcatheter (Stryker Neurovascular, Fremont, Calif., USA). In 2008, 1.5-mm sized coils first became available at our institution. No modified coils were used. In all patients, a balloon (Hyperglide or Hyperform; ev3, Irvine, Calif., USA) was placed for hemostatic prophylaxis; we did not inflate the balloons in any of the described cases. Procedure-related rupture was defined as contrast extravasation during treatment. 
Nguyen et al.: Expanding Endovascular Therapy of Very Small Ruptured Aneurysms with the 1.5-mm Coil

Table 1. Patient characteristics, coiling results, and patient outcome

\begin{tabular}{|c|c|c|c|c|c|c|c|c|c|}
\hline $\begin{array}{l}\text { Patient/ } \\
\text { gender }\end{array}$ & $\begin{array}{l}\text { WFNS } \\
\text { grade }\end{array}$ & $\begin{array}{l}\text { Aneurysm } \\
\text { size, mm }\end{array}$ & $\begin{array}{l}\text { Aneurysm } \\
\text { location }\end{array}$ & $\begin{array}{l}\text { Coil } \\
\text { used }\end{array}$ & Complication & $\begin{array}{l}\text { mRS } \\
6 \text { months }\end{array}$ & Retreat & Rebleed & $\begin{array}{l}\text { Follow- } \\
\text { up, } \\
\text { months }\end{array}$ \\
\hline $39 / \mathrm{f}$ & 1 & $3 \times 1.7$ & ACom & $\begin{array}{l}1.5 \mathrm{~mm} \\
\times 2 \mathrm{~cm}\end{array}$ & none & 0 & $\begin{array}{l}\text { coiling failed; } \\
\text { clipped }\end{array}$ & no & 16 \\
\hline $32 / \mathrm{f}$ & 4 & $3 \times 1.5$ & $\begin{array}{l}\text { carotid } \\
\text { terminus }\end{array}$ & $\begin{array}{l}1.5 \mathrm{~mm} \\
\times 4 \mathrm{~cm}\end{array}$ & none & 0 & $\begin{array}{l}\text { clipped } \\
\text { no residual }\end{array}$ & no & 9 \\
\hline $63 / f$ & 5 & 2 & SCA & $\begin{array}{l}1.5 \mathrm{~mm} \\
\times 2 \mathrm{~cm}\end{array}$ & $\begin{array}{l}\text { ventriculitis } \\
\text { death }\end{array}$ & 6 & $\mathrm{n} / \mathrm{a}$ & no & 3 \\
\hline $56 / \mathrm{m}$ & 4 & $3 \times 1.5$ & MCA & $\begin{array}{l}1.5 \mathrm{~mm} \\
\times 3 \mathrm{~cm}\end{array}$ & none & 0 & none & no & 62 \\
\hline $43 / \mathrm{m}$ & 3 & $3 \times 2$ & ACom & $\begin{array}{l}1.5 \mathrm{~mm} \\
\times 3 \mathrm{~cm}\end{array}$ & none & 0 & $\mathrm{n} / \mathrm{a}$ & no & 16 \\
\hline
\end{tabular}

WFNS = World Federation of Neurosurgical Societies; mRS = modified Rankin Scale; SCA = superior cerebellar artery.

Clinical Follow-Up

Clinical follow-up for patients was assessed using the Glasgow Outcome Sore. Good outcome was defined as Glasgow Outcome Sore 4 (moderate disability but independent) or 5 (good recovery).

\section{Results}

Eighty-one aneurysms were treated acutely with coils in 78 patients presenting with subarachnoid hemorrhage. The mean aneurysm size of ruptured aneurysms was $7 \mathrm{~mm}$ (range $2-40$ ). There were 5 patients with aneurysms of $3 \mathrm{~mm}$ of maximal diameter, of which the transverse diameter was $<2 \mathrm{~mm}$ in 3 patients. In all 5 patients, a single $1.5-\mathrm{mm}$ coil was inserted for aneurysm treatment without complication. Complete aneurysm occlusion was achieved in 1 patient (fig. 1), residual neck in 2, and residual aneurysm filling was seen in other 2 patients. Aneurysm recanalization was present in 2 patients with an anterior communicating artery aneurysm (ACom); a coiling attempt in 1 of these patients was unsuccessful due to inadvertent coil dislodging and secondary distal coil embolization, but secondary surgical clipping was successful (fig. 2). The other patient with a recanalized ACom decided to continue with conservative management. Another patient was retreated by surgical clipping for a residual wide-neck carotid terminus aneurysm.

One patient died of ventriculitis 3 weeks after presentation; all other patients had an excellent clinical outcome with no rebleed at follow-up (mean 21 months, range 1-62). For the 2 patients who underwent clipping, the end of the follow-up period was calculated as the time from the initial hemorrhage to the time of surgical clipping.

\section{Discussion}

In the ISAT trial, aneurysms less than $3 \mathrm{~mm}$ were not included in the trial, likely due to the unavailability of very small sized coils and at the time of the trial. This subgroup of patients has been found to be at higher risk of intraprocedural rupture [3-6]. The smaller confines within the aneurysm presents a technical challenge, with less degree of freedom (error) in the placement of any coil, microcatheter, or microguidewire. 
Nguyen et al.: Expanding Endovascular Therapy of Very Small Ruptured Aneurysms with the 1.5-mm Coil

Fig. 1. A 56-year-old male with a ruptured right MCA aneurysm, $3 \times 1.5 \mathrm{~mm}$ in diameter, before (a) and after (b) coiling with a $1.5-\mathrm{mm} \times 3-\mathrm{cm}$ coil.
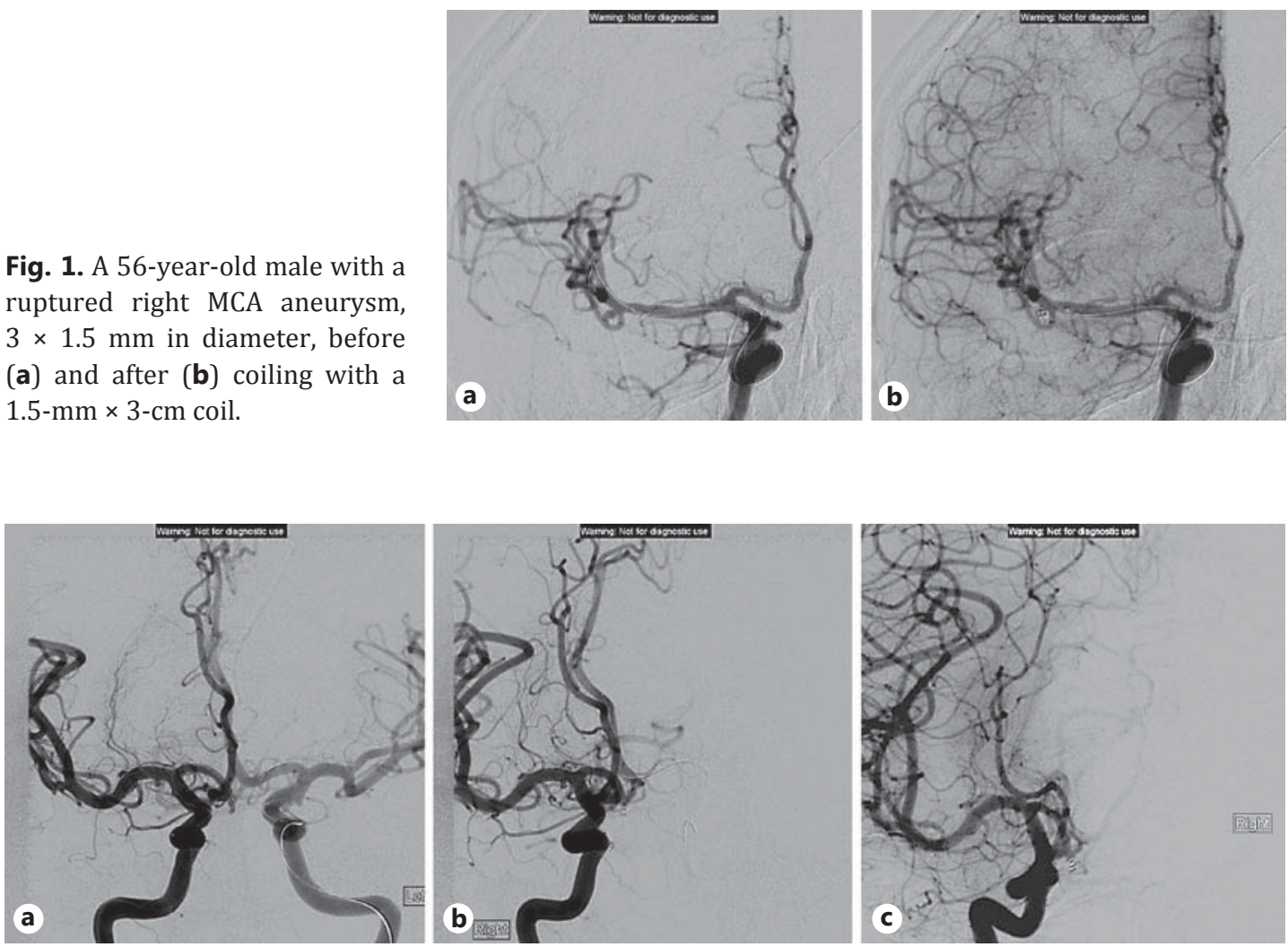

Fig. 2. A 39-year-old woman with a ruptured ACom artery aneurysm, $3 \times 1.7 \mathrm{~mm}$ in diameter, before (a) and after (b) coiling with a $1.5-\mathrm{mm} \times 2$-cm coil. Recurrent aneurysm (c) is seen at the 7-month follow-up.

In our series of ruptured aneurysms, the group with very small aneurysms ( $\leq 3 \mathrm{~mm})$ was a minority, forming approximately $7 \%$ of all ruptured aneurysms. When the $1.5-\mathrm{mm}$ coil became available, this enabled the neurointerventionalist to offer endovascular coiling to patients with very small aneurysms. In this small series of patients, we demonstrated safe and enabled adequate protection of patients from a rebleed in a small cohort, with no intraprocedural perforation, rupture, or thrombosis. Our objective was to coil the aneurysm with one coil, utilizing the smallest diameter so as to avert intraprocedural rupture, and with the shortest-length coil that would enable aneurysm occlusion. In all patients, a balloon was prepared for hemostatic prophylaxis, which, in a previous reported series, was associated with good outcome in the event of procedural rupture [3].

Several series have reported good results with coiling of very small ruptured aneurysms $(\leq 3 \mathrm{~mm})[7,8]$. In other series, even smaller ruptured aneurysms $(\leq 2 \mathrm{~mm})$ have been treated by coiling, including Gil et al.'s series of 4 patients [9] and Gupta et al.'s [10] series of 7 patients, both with good outcomes. Recently, Jindal et al. [11] shared their experience using 1-1.5-mm Target Nano coils (Stryker Neurovascular, Fremont, Calif., USA) in 14 aneurysms ranging from 1.5-3.5 mm in size; there were no immediate procedural complications reported. Techniques described to optimize procedure safety with coiling include use of a remodeling balloon to stabilize the tip of the microcatheter [9] and inserting the coil from the neck of the aneurysm to minimize the risk of procedural rupture.

The close follow-up of our patients demonstrated recurrent aneurysm in one third of the eligible patients, requiring retreatment with surgical clipping. In another patient, a residual 
wide-neck carotid terminus aneurysm was clipped after 9 months from the ictus to offer definitive treatment following stabilization by coiling. Despite the good aneurysm occlusion rates reported $[8,10]$, we continue to advocate close follow-up for recanalization in this small and select patient population.

Surgical clipping could have been an alternative treatment to coiling of very small aneurysms, but this also confers unique challenges to the surgeon in the acute phase. The vessel wall of the aneurysm may be too small or thin-walled to accept a clip without narrowing or tearing the parent vessel $[9,10]$, and the lack of clip purchase due to aneurysm size and geometry may likely constitute to increased failure rates. Furthermore, elderly, high-grade subarachnoid hemorrhage patients may not be ideal candidates for surgery.

\section{Conclusion}

The 1.5-mm coil may expand the treatment of patients with very small ruptured aneurysms to coiling, providing a temporizing protection to the site of rupture in the acute phase. If necessary, bridging with elective clipping may provide definitive aneurysm treatment.

\section{Disclosure Statement}

The authors have no pertinent disclosures.

\section{References}

1 Molyneux A, Kerr R, Stratton I, Sandercock P, Clark M, Shrimpton J, et al: International Subarachnoid Aneurysm Trial (ISAT) of neurosurgical clipping versus endovascular coiling in 2,143 patients with ruptured intracranial aneurysms: a randomized trial. Lancet 2002;26:1267-1274.

$>2$ Molyneux AJ, Kerr RSC, Birks J, Ramzi N, Yarnold J, Sneade M, Rischmiller JR, for the ISAT collaborators: Risk of recurrent subarachnoid hemorrhage, death, or dependence and standardised mortality ratios after clipping or coiling of an intracranial aneurysm in the International Subarachnoid Aneurysm Trial (ISAT): long-term follow-up. Lancet Neurol 2009;8:427-433.

3 Nguyen TN, Raymond J, Guilbert F, Roy D, Mahmoud M, Berube M, Weill A: Association of endovascular therapy of very small ruptured aneurysms with higher rates of procedure-related rupture. J Neurosurg 2008;108: 1088-1092.

$>4$ Rooij WJV, Keeren GJ, Peluso JPP, Sluzewski M: Clinical and angiographic results of coiling of 196 very small (< or $=3 \mathrm{~mm}$ ) intracranial aneurysms. AJNR Am J Neuroradiol 2009;30:835-839.

5 Schuette AJ, Hui FK, Spiotta AM, Obuchowski NA, Gupta R, Moskowitz SI, Tong FC, Dion JE, Cawley CM: Endovascular therapy of very small aneurysms of the anterior communicating artery: five-old increased incidence of rupture. Neurosurgery 2011;68:731-737.

6 Sluzewski M, Van Rooij WJ: Small aneurysm size is a risk factor for perforation during coiling. AJNR Am J Neuroradiol 2003;24:2122.

7 Chae KS, Jeon P, Kim KH, Kim ST, Kim HJ, Byun HS: Endovascular coil embolization of very small intracranial aneurysms. Korean J Radiol 2010;11:536-541.

8 Hwang JH, Roh HG, Chun YI, Kang HS, Choi JW, Moon WJ, Cho J, Moon CT, Koh YC: Endovascular coil embolization of very small intracranial aneurysms. Neuroradiology 2011;53:349-357.

-9 Gil A, Vega P, Murias E, Cuellar H: Balloon-assisted extrasaccular coil embolization technique for the treatment of very small cerebral aneurysms. J Neurosurg 2010;112:585-588.

10 Gupta V, Chugh M, Jha AN, Walia BS, Vaishya S: Coil embolization of very small (2 mm or smaller) berry aneurysms: feasibility and technical issues. AJNR Am J Neuroradiol 2009;30:308-314.

11 Jindal G, Miller T, Beaty N, Puri A, Gandhi D: Ultra-small diameter coils for treatment of intracranial aneurysms. Interv Neuroradiol 2015;21:50-54. 